\title{
A VIDA COMO VIR-A-ACEITAR: CONSIDERAÇÕES Austinianas SOBRE A MODERNIDADE
}

\author{
(Life as coming-to-accept: Austin-like considerations on modernity)
}

\author{
Fábio Luiz LOPES DA SILVA \\ (Universidade Federal de Santa Catarina)
}

\begin{abstract}
According to Austin, the first condition of happiness of a performative utterance is the existence of "an accepted conventional procedure". We have a curious situation here, and Austin recognizes it, at least in part. In fact, if a performative - the act of accepting - is inscribed in the very structure of performativity, then every performative - including accepting - presupposes an act of accepting, which, in its turn, presupposes an act of accepting, and so on. Accepting - not merely a regular performative, but a condition of the happiness of every performative - is, in the final analysis, is impossible to totalize.

In this essay, following Austin's statements, I make an attempt to define life as comingto-accept, a topic analogous to the classical topic of life as coming-to-be. After this, I will try to articulate Austinian philosophy of language to Contardo Calligaris' considerations on modernity, in order to delineate the modern way of dealing with life as comingto-accept.
\end{abstract}

KEY-WORDS: performativity; responsability; act of accepting; modernity.

RESUMO: Austin, como se sabe, toma a existência de um procedimento convencional aceito como condição primeira de felicidade de qualquer performativo. Mas isso coloca um problema, que o filósofo inglês não chega a considerar até suas últimas conseqüiências. Refiro-me ao fato de que um certo performativo - a aceitação - está inscrito na própria estrutura da performatividade. Ou seja, todo performativo exige um 'Aceito', que, por sua vez, exige um 'Aceito' - e assim ao infinito. Aceitar - essa condição de felicidade de todo performativo - é um ato, no limite, impossivel de ser objetivado.

Trata-se, neste ensaio, de pensar, a partir de Austin, a vida como um vir-a-aceitar, tema correlativo ao já clássico tópico da vida como vir-a-ser. Trata-se, em seguida, de pensar a forma propriamente moderna de lidar com esse vir-a-aceitar. Para tanto, vou propor uma articulação entre a filosofia austiniana e as reflexões de Calligaris (1997) sobre a modernidade.

PALAVRAS-CHAVE: performatividade; responsabilidade; ato de aceitar; modernidade. 


\section{Introdução}

Neste ensaio, procurarei retomar a discussão derridiana acerca do tema da responsabilidade, cujo fundamento é uma leitura radical da obra de John Austin.

Segundo Derrida (1991), How to do things with words, de Austin, traz todos os elementos para que se compreenda a assunção da responsabilidade como um gesto habitado pelo que o filósofo argelino chama de 'inconsciência estrutural'.

Derrida chega a essa conclusão por um caminho cujo ponto de partida é utilizar os próprios enunciados de Austin com o propósito de questionar a distinção austiniana entre os usos sérios e não-sérios da linguagem.

Meu ponto de partida será outro. Trata-se da problematização da presença do termo aceito naquela que é, segundo Austin (1999: 16, tradução minha), a primeira regra capaz de fazer um performativo existir e funcionar:

(A.1) Deve existir um procedimento convencional aceito, que apresente determinado efeito convencional e que inclua o proferimento de certas palavras, por certas pessoas, e em certas circunstâncias. ${ }^{1}$

Tentarei mostrar que a inclusão de um certo performativo - o dispositivo da aceitação - na própria estrutura da performatividade coloca-nos diante de uma espiral em abismo: os performativos precisam ser aceitos mas, se aceitar é também um performativo, ele, como qualquer de seus pares, precisa ser aceito. $\mathrm{E}$ assim ao infinito.

Austin, portanto, permite dizer que a aceitação, como ato, é, no limite, impossível de ser inteiramente objetivada. ${ }^{2} \mathrm{E}$, se os performativos em geral dependem do dispositivo da aceitação, nenhum deles, por extensão,

1. Embora em todas as demais citações de Austin eu acompanhe os termos da tradução proposta por Danilo Marcondes de Souza Filho, não o farei, em parte, no caso regra (A.1). O original diz, a certa altura, "accepted conventional procedure". Salvo engano, o escopo de "accepted" é, pois, "conventional procedure". A solução de Souza Filho é bem diferente: "procedimento convencionalmente aceito". O adjetivo "conventional" é transformado em advérbio que incide sobre "accepted". De resto, o termo "accepted" aparece grifado no original, mas não na versão traduzida para o português. Para uma crítica geral à tradução de Souza Filho, ver Rajagopalan (1990).

2. O termo 'objetivada' - muito preciso - foi sugestão de meu aluno e orientando Atílio Butturi Jr. 
se objetiva inteiramente. Autorizo-me, por isso, a especular sobre a vida como um vir-a-aceitar, tema correlativo ao já clássico tópico do vir-a-ser.

Por fim, procurarei refletir sobre o ato de aceitação não apenas em termos abstratos e gerais, mas como "realidade histórica" ${ }^{3}$ Em particular, abordarei o dispositivo da aceitação na modernidade. Para tanto, vou propor uma articulação das idéias de Austin com as reflexões de Contardo Calligaris acerca da modernidade e suas vicissitudes.

\section{O espectro da infelicidade}

"Herdar é ter que escolher", ensina Jacques Derrida. ${ }^{4}$ E ele mesmo, coerentemente, voluntariamente, para herdar, escolhe. Ao abordar, por exemplo, a obra de John Austin, não lhe interessa reduzi-la a uma teoria dos atos de fala. Parece-lhe bem mais estimulante dar atenção ao que a promessa de formular essa teoria, para ser empenhada, não apenas adiou para um futuro incerto, mas sobretudo deixou para trás, como se de dejetos se tratasse.

Transformar dejetos em objetos: não foi isso, afinal, o que o próprio Austin fez quando identificou e tomou a sério os performativos? Onde mais ele foi recolhê-los, senão na lata de lixo da filosofia (da linguagem), cuja história, até então, fora maciçamente consagrada à consideração das afirmações?

Tomar a sério os dejetos: mandamento austiniano, que Derrida, à sua maneira, isto é, austinianamente, toma a sério, identificando e tomando a sério precisamente os dejetos deixados para trás pelo próprio Austin.

\footnotetext{
3. As aspas se justificam por dois motivos. Primeiro, porque, se a possibilidade da infelicidade é um espectro ineliminável, então toda aceitação e, por conseguinte, toda performatividade nunca se presentificam inteiramente - nunca, portanto, se tornam realidade plena. $\mathrm{O}$ outro motivo diz respeito à historicidade. Trata-se de um conceito que precisa ser relativizado - "aspeado" - porque, a meu juízo, é vazado por algo que é de ordem estrutural. Ou melhor: não exatamente algo, mas um não-algo: uma falta-a-ser. Voltarei a esse ponto na parte final do ensaio.

4. A frase é, na verdade, uma condensação, por mim proposta, da seguinte passagem: "Se a legibilidade de um legado fosse dada, natural, transparente, unívoca, se ela não pedisse e não desafiasse ao mesmo tempo a interpretação, não se teria nunca o que herdar. Seríamos afetados por isso como uma causa - natural ou genética. [...] A escolha crítica pedida por toda reafirmação de herança diz respeito também, exatamente como a memória, à condição de finitude." (Derrida, 1994: 33)
} 
Que dejetos? Por exemplo, todo o campo recortado pelo que Austin chama de usos não-sérios da linguagem. Trata-se, então, para Derrida, de tomar a sério, entre outras coisas, o que Austin considera não-sério. Tratase, mais exatamente, de tomar a sério, para questioná-la, a distinção austiniana entre seriedade e não-seriedade.

Marco zero desse exercício: a passagem de How to do things with words em que Austin justamente (ou seria o caso de dizer 'injustamente'?) define a não-seriedade. Ou melhor: ele não a define. Limita-se, antes, a elencar exemplos do que julga ser usos não-sérios da linguagem: ${ }^{5}$

[O]s performativos enquanto proferimentos herdam outros tipos de males que infectam todo e qualquer proferimento. Estes, embora possam ser enquadrados em uma regra mais geral, foram, no momento, deliberadamente excluídos. O que quero dizer é o seguinte: um proferimento performativo será, digamos, vazio ou nulo de um modo peculiar, se dito por um ator em cena, ou se introduzido em um poema, ou falado em um solilóquio. De modo similar, isso vale para todo e qualquer proferimento, pois trata-se de uma mudança de rumo em circunstâncias especiais. Compreensivelmente a linguagem, em tais circunstâncias, não é lavada [sic] ou usada a sério, mas de forma parasitária em relação a seu uso normal, forma esta que se inclui na doutrina dos estiolamentos da linguagem. Tudo isso fica excluído de nossas considerações. Nossos proferimentos performativos, felizes ou não, devem ser entendidos como ocorrendo em circunstâncias ordinárias. (Austin, 1990: 36)

A Derrida não escapa a presença do quantificador todos - tão caro aos lógicos - na proposição estabelecida por Austin. Essa presença, para o filósofo argelino, é profundamente perturbadora:

[É preciso sublinhar] que o valor de risco ou de sujeição ao fracasso, ainda que possa afetar a priori, Austin reconhece-o, a totalidade dos atos, não é interrogada como um predicado essencial ou como lei. Austin não se pergunta que conseqüências de um possível - um risco possível - ser sempre possível, constituir de qualquer modo uma possibilidade necessária. (Derrida, 1991: 365-6)

\section{Conclusão de Derrida (1991: 368):}

[U]m performativo conseguido é forçosamente um performativo 'impuro', para retomar a palavra que Austin avançará mais adiante, quando reconhecer que não existe performativo 'puro'.

5. Pudera: ao tentar identificar a natureza do ato de definir, o próprio Austin (1990: 124) observa que se trata de algo "difíc[il] de definir". O caráter problemático do gesto de definir o que é definir obviamente infectará qualquer tentativa de definição do que quer que seja. 
Algo parecido poderia ser dito das traduções, se bem que Austin não chegue a incluir explicitamente o ato de traduzir entre os elementos do conjunto dos usos não-sérios da linguagem. Mas é quase certo que o filósofo inglês estaria propenso a fazê-lo. Em todo caso, outros, em seu nome ou por conta própria, o fariam - e isso basta para que, parafraseando o ato (de fala) desconstrutivo de Derrida, eu lance a seguinte questão: um enunciado que não possa ser traduzido é um enunciado? Se a resposta, como parece ser o caso, for negativa, então a possibilidade de tradução é constitutiva da originalidade do enunciado original. Não haveria, pois, originalidade inteiramente pura. Não haveria originalidade nem qualquer enunciado de falante nativo que não fossem habitados pelo fantasma do estrangeiro, da tradução - e, como se diz freqüentemente desta última, da traição.

A traição ronda: não há legitimidade pura. O filósofo argelino voltará a esse tema ao tratar da assinatura - figura extrema da assunção de responsabilidade. "O que é uma assinatura que não possa ser repetida e, no limite, por sua reprodutibilidade necessária, falsificada?”, pergunta-se Derrida. O que é, portanto, a legitimidade se a possibilidade do ilegítimo continua a constituir a sua estrutura?

O ilegítimo, o traiçoeiro, o não-sério: formas específicas do que Austin reúne sob o rótulo de infelicidades. Sendo assim, todas as questões que aqui se puseram podem ser resumidas em uma fórmula geral, assinada por Derrida. Esta: "O que será um sucesso quando a possibilidade de um fracasso continua a constituir a sua estrutura?” (Derrida 1991: 366)

Proponho-me, doravante, por razões que logo ficarão claras, a me perguntar sobre a possibilidade ineliminável do fracasso como elemento constituinte da estrutura de um performativo em particular: a aceitação.

\section{A vida como vir-a-aceitar}

Recordo, de saída, que, ao tentar explicitar as condições de felicidade de um ato de fala, Austin estipula um conjunto de regras, das quais, a propósito, já citei a primeira. Ei-las:

(A.1) Deve existir um procedimento convencional aceito, que apresente determinado efeito convencional e que inclua o proferimento de certas palavras, por certas pessoas, e em certas circunstâncias; e além disso, que 
(A.2) as pessoas e as circunstâncias particulares, em cada caso, devem ser adequadas ao procedimento específico invocado.

(B.1) O procedimento tem de ser executado por todos os participantes de modo correto e

(B.2) completo.

(Г.1) No casos em que, como ocorre freqüentemente, o procedimento é concebido visa às pessoas com seus sentimentos e pensamentos, ou visa à deflagração de uma conduta correspondente por parte de alguns dos participantes, então aquele que participa do procedimento, e o invoca deve ter de fato tais sentimentos e pensamentos, e os participantes devem ter a intenção de se conduzirem de maneira adequada, e além disso,

(Г.2) devem realmente conduzir-se dessa maneira subseqüentemente. (Austin, 1990: 31$)^{6}$

Ato contínuo, com a coragem intelectual que o caracteriza, Austin passa a problematizar as suas próprias palavras. Refere-se, por exemplo, ao fato de que a classificação de certas infelicidades é muito difícil e, por vezes, impossível, a não ser por força de um gesto mais ou menos arbitrário. Limito-me a citar um exemplo dessas eventuais confusões:

Uma outra situação crítica seria a seguinte: em uma ilha deserta alguém pode me dizer 'Vá apanhar lenha' e eu respondo 'Não recebo ordens suas', ou, ainda, 'Você não tem o direito de me dar ordens', ou 'Não aceito suas ordens quando você está tentando afirmar a sua autoridade' (que posso aceitar ou não) em uma ilha deserta' . O caso contrário seria se você fosse o capitão do navio, tendo então essa autoridade. [...]

[P]oderíamos dizer, considerando um caso do tipo A.2 (má aplicação): o procedimento - isto é, o proferimento de certas palavras, etc. - era correto e foi aceito, embora estivessem erradas as circunstâncias de invocação e as pessoas que o invocaram. [...]

Poderíamos ainda dizer, levando o caso para a regra B.2. [...]: o procedimento não foi completamente executado por ser necessário que o objeto do verbo 'eu ordeno que' estabeleça, mediante, um procedimento prévio, tácito ou explícito, que a pessoa que vai dar a ordem tenha autoridade [...]. (Austin, 1990: 40)

Mas o que de fato me interessa discutir aqui diz propriamente respeito aos questionamentos que, um pouco antes da passagem que acabei de destacar, Austin dirige ao conteúdo específico da primeira regra. Não custa recordá-la:

6. Salvo, em parte, a regra (A.1), por mim traduzida a partir do original em inglês, conforme expliquei na nota 1 , acima. 
(A.1) Deve existir um procedimento convencional aceito, que apresente determinado efeito convencional e que inclua o proferimento de certas palavras, por certas pessoas, e em certas circunstâncias.

Austin discute longamente a adequação do termo 'aceito' no enunciado (A.1). Conclui, dessa reflexão, que a palavra deve ser mantida, com a condição de se ter em conta que "para um procedimento ser aceito pressupõe-se algo mais do que ser considerado efetiva e genericamente usado, até mesmo pelas pessoas envolvidas". (Austin, 1990: 41)

Mais ele não diz sobre o assunto. Em todo caso, ao destacar a complexidade do gesto de aceitar, Austin está, no mínimo, dando a entender que se trata de um performativo a ser esmiuçado.

Ora, se aceitar é mesmo um performativo e, além disso, se aceitar é um ato cuja execução está inscrita nas próprias condições de realização dos performativos em geral, então, para que performativos sejam realizáveis, é preciso que ao menos um deles - precisamente a aceitação - já tenha se realizado. Bem se vê que estamos diante de uma situação paradoxal: todo performativo supõe um 'Aceito' que, por sua vez, supõe um 'Aceito', que supõe um 'Aceito'... É essa a complexidade - a irresolubilidade, a rigor do ato de aceitar, que Austin, por seu turno, indicou, mas não chegou a aceitar inteiramente.

De certo modo, o exposto no parágrafo anterior torna perdoável o recuo de Austin. Afinal, a existência de qualquer ato convencional (de fala), como salientei, é vazada por uma aceitação que nunca se objetiva inteiramente.

De certo modo, o exposto no penúltimo parágrafo não torna perdoável o recuo de Austin. É que constatar - essa palavra tão perigosa... - que a aceitação não se objetiva inteiramente não é o mesmo que dizer que não haja performativos nem que não se possa assumir, na forma explícita ou implícita de um 'Eu aceito', a responsabilidade por eles. Constatar - essa palavra tão perigosa... - que a aceitação não se objetiva de todo implica, paradoxalmente, (tentar) aceitar o peso da responsabilidade de que o gesto de responsabilizar-se nunca se completa.

Aceitar o que é impossível de ser aceito: eis, talvez, uma boa definição do que seja a vida. A vida como vir-a-ser é, desde Heráclito, tema comum 
em certos círculos filosóficos. Depois de Austin, fica a sugestão de tomar o tema do vir-a-ser como correlativo e, quem sabe, homólogo ao do vir-aaceitar.

\section{A modernidade e a aceitação do que não pode ser aceito}

Aceitar é um ato complexo - irresolvível, no limite. Abre-se ao infinito - mas talvez possa ser pensado, também, "historicamente". ${ }^{7}$ É o que, com base em um ensaio de Contardo Calligaris, proponho-me a fazer a partir de agora. ${ }^{8}$

Para Calligaris, vale para a modernidade o que Freud disse acerca do processo civilizatório em geral: exige-se do sujeito que ele internalize a autoridade. É isso, segundo Calligaris (1997: 186), o que garante que consigamos "conviver sem que seja necessária a presença de um policial ao nosso lado a cada vez que nos encontramos com nosso semelhante". Mas, para o psicanalista italiano, há algo que caracteriza e distingue modernamente a internalização da Lei: o sujeito moderno a introjeta recalcando a sua origem exterior. Valendo-se de conceitos herdados da Escola de Frankfurt, Calligaris (1997: 187) descreve essa condição como "uma passagem da razão objetiva para uma razão subjetiva". Trocando em miúdos, não se trata de dizer que o sujeito moderno necessariamente recuse os conteúdos do sistema jurídico vigente ou, para falar em termos ainda mais amplos, das tradições que o precedem; a rigor, ele bem pode aceitar esses conteúdos em parte ou totalmente, desde que - e aí está o dado crucial - os submeta, antes, a uma espécie de tribunal interno.

Comumente, a modernidade é vista como aquilo que se opõe à tradição. Para Calligaris, não é esse o caso - e isso por duas razões. Acabei de expor a primeira delas: os conteúdos da tradição podem perfeitamente subsistir entre nós, desde que aprovados pelo sujeito - privatizados, por assim dizer, por força do que Calligaris chama de tribunal interno. Já a segunda

7. Sobre as aspas, ver a nota 3 , acima.

8. Conheço, naturalmente, o debate acerca das incompatibilidades entre a psicanálise e a desconstrução. Mas aqui não se trata de ser derridiano ou lacaniano ou calligariano no sentido habitual desses termos. Trata-se, antes, de respeitar esses autores à maneira de Foucault (1984: 143) em sua relação com a obra de Nietzsche: para o filósofo francês, a melhor forma de homenagear e repetir Nietzsche é "utilizá-lo, distorcê-lo, fazê-lo ranger". 
razão leva o psicanalista italiano ao ponto de poder falar em uma tradição propriamente moderna: é que, segundo Calligaris, erigir esse tribunal interno - colocar, enfim, o indivíduo no lugar de valor supremo e medida de todas as coisas - é a forma moderna de se submeter a uma obrigação. Eis por que, para ele,

Evidentemente, o que o indivíduo de nossa sociedade não pode escutar é que a individualidade ou individualismo [...] é justamente o que a sua tradição lhe manda valorizar. (Calligaris, 1997: 189)

"Seja livre": lei que nos captura lá onde pensamos estar nos livrando de toda autoridade externa. "Seja livre", isto é, "Livre-se, inclusive de mim, se for capaz": mandamento terrível, paradoxal e, por isso, impossível de ser satisfeito.

Uma lei que exige o ódio a todas as leis e, por extensão, a ela própria: aí está o que, em última instância, dirigiria as nossas vidas. Trata-se, obviamente, de uma força que se equilibra no ponto morto entre o fascismo e o liberalismo - lugar em que vigora o grau zero da legitimidade da lei, seja por uma auto-anulação explícita ("Livre-se, inclusive, de mim"), seja por conta da desconfiança que pesa sobre toda forma excessiva de poder.

Parece, pois, que, para Calligaris, o preço da modernidade é a convivência contínua com a possibilidade da disrupção social: ser indivíduo é estar sempre a esgarçar o lugar da lei como instância em que um terceiro medeia toda relação dual, todo encontro com o semelhante. Prefiguração de um mundo paranóico em que cada semelhante passa a ser visto como um agressor em potencial, uma vez que não sabemos até onde o seu tribunal interno permite que ele aja com a consciência tranqüila.

Ora, não é difícil antever o que está no limiar desse regime de desconfianças recíprocas. Trata-se do que Jurandir Freire Costa (1993) chama de cultura da violência - um estado de coisas em que a brutalidade se impessoaliza, podendo partir de qualquer lugar. Por segurança, antecipamo-nos ao ataque do outro - somos desde logo agressivos com ele.

Mas o esgarçamento desse terceiro mediador pode gerar ainda uma outra espécie de contingência: aquela em que, entregue a si mesmo, o indivíduo passa a uma glorificação do "self, do eu privado, único": cultura do narcisismo. 
Cultura do narcisismo, cultura do conformismo. Afinal, para Calligaris (1997: 190),

Se não temos uma herança que nos possa sustentar como sujeitos, só no olhar dos semelhantes podemos encontrar a confirmação de que somos tão amáveis como gostaríamos de ser aos nossos próprios olhos.

A paranóia ou o narcisismo necessariamente conformista são, se nada for feito em contrário, o nosso destino. Mas o que pode ser feito em contrário? Muito pouco, segundo Calligaris. Por um lado, práticas como a psicanálise - embora sejam filhas da modernidade e de seus imperativos - podem dar a sua (pequena) contribuição, levantando a barra do recalque e, assim, fazendo o sujeito escutar o que ele recusa.

Em larga escala, resta a política, que, para não ser uma impostura, deve fomentar continuamente a construção de uma sociedade civil - uma que esteja ao nosso alcance, isto é, "não uma comunidade, nem uma sociedade contra os indivíduos, mas uma sociedade de indivíduos". (Calligaris, 1997: 192)

\section{Aceito, logo existe}

Em How to do things with words, Austin, por seu lado, faz muito poucas referências explícitas à política. Uma delas - senão a única - surge na Conferência III, ao fim da discussão, por mim mencionada acima, em torno do exemplo da natureza da infelicidade que afeta a tentativa de emitir uma ordem a alguém em uma ilha deserta:

Esta é, certamente, uma das incertezas - de caráter puramente geral - que subjazem ao debate que se apresenta no campo da teoria política quando discutimos se há ou não, ou se deveria haver, um contrato social. (Austin, 1990: 40)

Faltou a Austin acrescentar que toda a discussão acerca do contrato social só se coloca na modernidade, isto é, quando, para repetir o que eu disse há pouco, a possibilidade da disrupção social se impõe com toda a sua força. Em todo caso, como pensar austinianamente a descontinuidade que intervém entre a modernidade e tudo que dela se distingue? 
Retorno, para começar, à regra (A.1), várias vezes invocada neste ensaio. Acerca dela, é preciso acrescentar que, para além de discutir a presença e a necessidade do termo aceito na fórmula, Austin também questiona a pertinência do verbo existir - e o faz da seguinte maneira:

[C]abe perguntar o que se quer dizer com a sugestão de que um procedimento pode sequer existir, o que é diferente da questão de se um procedimento é aceito e por que o grupo é aceito ou não.

(I) Há o caso de procedimentos que 'não mais existem', no sentido de terem sido outrora aceitos, já não mais o são em geral ou mesmo por alguém, como no caso do duelo.

(II) Há também o caso de procedimentos recentemente inaugurados. Por vezes estes podem 'dar certo' - tal como no caso do rugby, com o jogador que primeiro pegou a bola com as mãos e saiu correndo. Dar certo é essencial, a despeito de sua terminologia suspeita. (Austin, 1990: 41)

Sobressai dessa discussão que, para Austin, existir como procedimento e ser aceito como procedimento são duas coisas distintas, se bem que relacionadas. Tendo isso em conta, arrisco-me a dizer que, a meu juízo, o que diferencia o sujeito moderno é o modo específico como tenta (ou, antes, é obrigado a tentar) articular existência e aceitação. Para dizê-lo de uma vez por todas, o próprio do sujeito moderno é procurar (ou, antes, ser obrigado a procurar) subordinar as regras enunciadas por Austin a uma proposição que, provocativamente, vou estabelecer sob uma forma referida ao cogito cartesiano: "Aceito, logo existe".

Mas, se, como repetidamente afirmei, a aceitação (e tudo que dela se segue) nunca se completa inteiramente, o sujeito da modernidade deve, então, ser visto como aquele que não é capaz de suportar essa incompletude. Ele tenta obturá-la absolutizando a força do 'Aceito' - quer dizer, absolutizando a força do 'Eu' que precede o verbo -, a tal ponto que a própria existência do mundo (simbólico) emana desse Eu que aceita.

O sujeito não-moderno, por outro lado, aceita - ou pelo menos, tenta aceitar - a impossibilidade de aceitar inteiramente: (tenta) aceita(r), enfim, a presença nele, sujeito, de uma alteridade radical (a "origem exterior", de que fala Calligaris), não apenas sob a forma dos "procedimentos convencionais" que ele, sujeito, insiste em repetir, mas sobretudo sob a forma desse Outro que ele, sujeito, insiste em acolher e que se presentifica - ou melhor: se ausentifica - como uma falta-a-aceitar. 
Aceitar o Outro como isso que falta a ser aceito é, se acreditarmos em Contardo Calligaris, tudo o que a modernidade recusa. Mas recusar o Outro tem um preço: o peso infinito do paradoxo de que, recusado, o Outro retorna, sim, como violência e narcisismo, mas também, e sobretudo, como um monstro que esmaga o sujeito - um buraco negro que aspira todas as suas energias libertárias.

Recebido em abril de 2007 Aprovado em novembro de 2008 E-mail: flopes@cce.ufsc.br

\section{REFERÊNCIAS Bibliográficas}

Austin, J. 1990. Quando dizer é fazer. Tradução de Danilo Marcondes de Souza Filho. Porto Alegre: Artes Médicas.

. How to do things with words. 1999. Cambridge, Mass.: Harvard University Press.

Calligaris, C. 1997. Sociedade e indivíduo. In: M. Fleig (org.). Psicanálise e Sintoma Social. São Leopoldo: Unisinos, 1997, pp. 183-196.

Costa, J. F. 1993. O medo social. Veja: 25 anos. Reflexões Para o Futuro. Abril: São Paulo, 1993, pp. 82-89.

Derrida, J. 1994. Espectros de Marx. Tradução de Anamaria Skinner. Rio de Janeiro: Relume-Dumará.

. 1991. 'Assinatura acontecimento contexto'. In: Margens da Filosofia. Tradução de Joaquim Torres Costa e António M. Magalhães. Campinas: Papirus, pp. 349-373.

Foucault, M. 1984. Microfísica do Poder. Tradução de Roberto Machado. Rio de Janeiro: Graal.

Rajagopalan, K. 1990. Dos diversos dizeres sobre o fazer. D.E.L.T.A., 6.2: 223-254. 